\title{
'The smiles that we create are worth every minute of my time'
}

\section{By Kate Quinlan}

We meet three dental professionals who provide charitable dental services to homeless and other vulnerable people.

\section{Andrea Johnson}

Background: Andrea Johnson is a Dental Technician (BSc Hons, LOTA) from Sutton in Ashfield, Nottinghamshire. She is Orthodontic \& Maxillofacial Laboratory Manager, Deputy Lead for Quality \& Clinical Governance OMFS, and a Quality Improvement Coach at Montagu Hospital in Mexborough, South Yorkshire. Andrea is also the Chair of the Orthodontic Technicians Association and Chair and co-founder of registered charity Den-Tech.

\section{Q. What is Den-Tech?}

Den-Tech was set up to relieve poverty by the provision of affordable dental appliances to those patients who are in need and unable to afford such items and in furtherance of this, to provide training, mentoring and education for dental technicians in developing countries to enable them to supply appropriate quality dental appliances.

\section{Q. What inspired you to set up Den-Tech?} In 2016 I was invited alongside fellow technician Andrew Sinclair to volunteer with a dental charity that was carrying out volunteer work in Uganda. I didn't think I would be much use as a technician as they only carried out clinical work. However, I went along and found it to be quite an eye opener. You never really appreciate these organisations and the work they do until you see and experience it first-hand. They/we did some fabulous work over the two weeks and managed to get a lot of people out of pain; we referred them for further help if we couldn't help there and then and we gave a lot of oral health advice.

Throughout the whole experience I was acutely aware that although these people

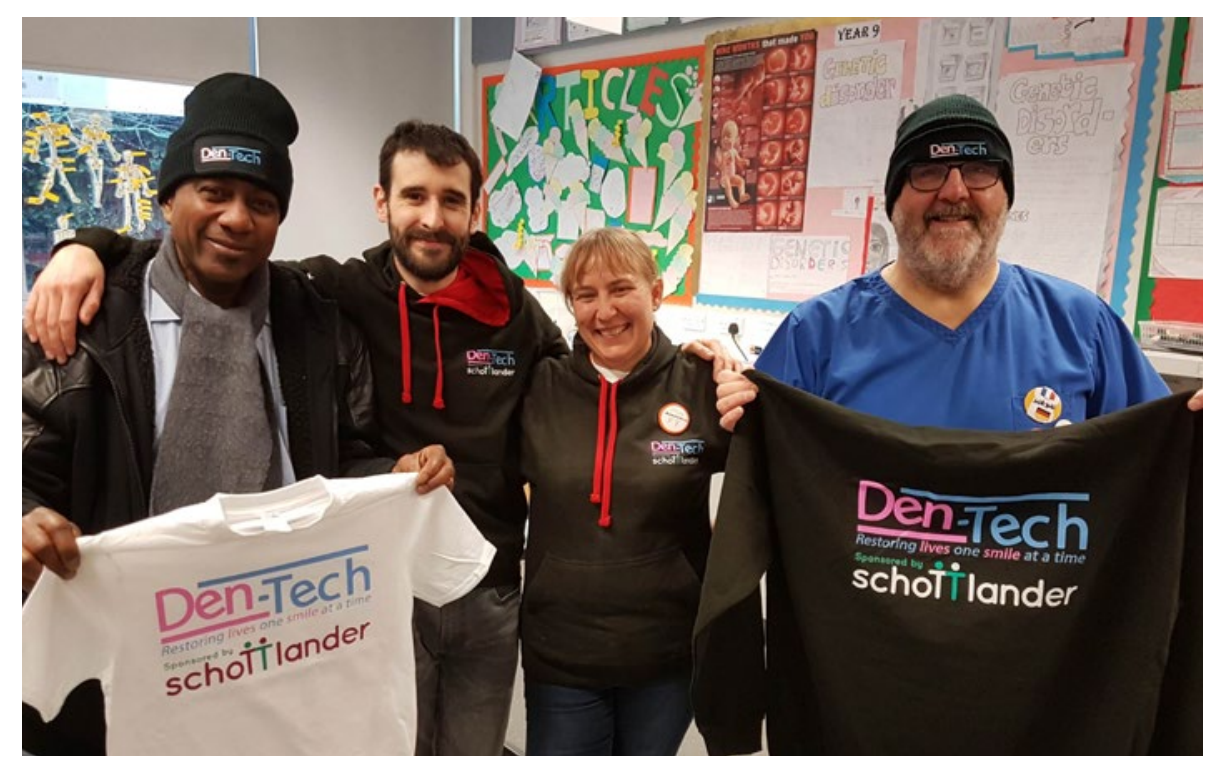

Andrea Johnson (centre), dental technician and co-founder of registered charity Den-Tech

\section{'Throughout the whole experience I was acutely aware that although these people were now out of pain they were left with large unrestored gaps...'}

were now out of pain they were left with large unrestored gaps which restricts the ability to eat, affects speech and appearance and can be quite distressing. Andrew and I realised that we were in a position to try and help complete this cycle of care by providing the lab service to restore the patients.

\section{Q. How and when did you set up the} charity?

After much deliberation and discussion in 2017 Andrew and I decided to set up Den-Tech. Andrew has experience in setting up and running a charity so he was the person that liaised with the charity commission and took the primary role in getting this side of things in place. However, we knew we couldn't do this alone so we looked for suitable people to join our board of trustees. Our initial line up was myself, Andrew, Professor Robert Williams, Edward Mapley, Jade Oakes and Delroy Reeves. Since then Prof Bob has stepped back into retirement and we have been very fortunate to enlist the services of Dentist Sami Stagnell onto our board of trustees. His knowledge and clinical perspective will be incredibly valuable to us. We have 
also, as we have got busier, enlisted the help of Carolyn Taylor who is our treasurer and Darren Ware who is our volunteer coordinator.

Everyone who is on the board of trustees or the committee is a volunteer with their own jobs and lives they are trying to juggle in addition to helping us, but we really couldn't do it without them.

\section{Q. What activities are Den-Tech involved with in a typical year?}

Den-Tech is pretty unique in the UK and as such the demand for our services is quite high but we are also quite young and so need to try and manage our activities within the constraints of the meagre resources we have. Having said that I believe we are achieving a lot despite this. This year we have sent four pallets of donated equipment to the University of Puthisastra in Cambodia as we are helping them to establish a crown and bridge training facility. We are working with two universities and a health institution in Uganda to help establish teaching and training facilities in the universities and a working dental laboratory in the health institution. We will be offering training and support to all of these for the foreseeable future.

We have also set up a project called 'Vets Bite Back' to establish a fully functional dental clinic and basic on site laboratory at a Veterans Walk-in Centre in Southampton with a view to expanding this model out to other areas around the country once the pilot project is up and running. I am very lucky to have Sami as my project lead on the clinical side of this.

\section{Q. Can you describe Den-Tech's work in the} Christmas week?

Den-Tech works alongside the very well established Crisis at Christmas clinical team to provide an onsite, same day denture service for their homeless guests. We achieve this by setting up a 'field laboratory' in their North London residential centre and ensure that there are dental technician volunteers there every day to provide this service.

Within the Den-Tech lab setting we have up to four volunteers onsite per day; the Crisis centre itself has a huge amount more. It is an amazing service they offer their guests. The services they offer over the Christmas week range from a full head to toe medical check up to housing support, job searches, IT help, new clothing, food, a bed for the week, people to sit and chat with them, games etc... the list just goes on.

In our first year offering this service we made 24 same day dentures over the course of the Christmas week; in the second year we made 32 . We are just about to embark on year three.

\section{Q. How do you fund the materials?}

The only way we can offer this and any of our other services is through the kindness offered to relieve me on Christmas Day so that I may go home and see my family for the day. So, we do a handover Christmas Eve and I head home in the afternoon/early evening, spend the day with my family on Christmas Day and then head back on Boxing Day morning for the hand back to myself. It is tough as I live around a three-hour drive away but my daughter is grown up enough now to understand and is very supportive of the work the we do; the happiness and smiles that we create are worth every minute of my time.

\section{'The only way we can offer this and any of our other services is through the kindness and generosity of donors.'}

and generosity of donors, whether that be donating items of material and equipment or monetary donations towards our work. This initial set up has also relied very heavily on my own and the other trustees' own personal resources. However, we are starting to get some amazing support from companies such as NSK who donated lab motors and handpieces to us, Schottlander who sponsored our hoodies and T-shirts for our volunteers, and Clyde Munro who have sent us a pallet of impression trays. We still need much more to keep the service running but it is a good start.

\section{Q. Do you see patients again/is there a follow up?}

As this particular service only runs alongside Crisis over the Christmas week a local dental practice has very kindly offered to see our patients for follow ups after the service has closed. We do of course sometimes see the same patients again year on year when we return and we review them then too should they wish and require it.

\section{Q. Do you have time to celebrate the festive} season with your family?

I arrive onsite the day before the service starts to get everything set up and in place and then basically spend the entire week working in the lab alongside my volunteers. I then close it down afterwards. However, I have been very lucky so far in that one of my trustees, Edward Mapley, has very kindly

\section{Q. Would you like others to volunteer for Den-Tech?}

I would love anyone within the dental team that feels that they can contribute to the work we do to get involved. Our primary service is of course the laboratory side but we welcome help from anyone and are real team players. We have other projects that are in the pipeline that will require the skills of the clinical team as well as the lab side so please if anyone wishes to help out in any way at all either by offering their time, skills, resources, fundraising or even getting more involved with the organisation and running of the charity, helping out with the website, social media etc, we have many ways in which people can help. Just visit www.den-tech.org, Facebook@Dentech1, Twitter @Den-Tech_ charity or email me on andreajohnson0705@ gmail.com.

\section{Natalie Bradley}

Background: Natalie Bradley is a Specialist Registrar in Special Care Dentistry working at Guy's Hospital in London and East Surrey Hospital in Redhill. Natalie has experience working in general, hospital and community dental settings. She is an NHS Clinical Entrepreneur working on solutions to help vulnerable people access dentistry and is an Alumnus of the Office of the Chief Dental Officer and Faculty of Medical Leadership and Management Scheme 2019. She also volunteers for the homeless charity Crisis over the Christmas period. 
Q. When did you first volunteer for Crisis at Christmas and what inspired you to help?

Over three years ago. I was inspired by one of my mentors to volunteer and had an interest in working with socially excluded patient groups after seeing many of them having to access emergency dental care at an emergency walk-in clinic I worked at.

Q. Can you describe your involvement over the Christmas period last year? I was one of the shift organisers for the service. This involved organising volunteers on the day, setting up the dental vans and decontamination area (a bit of a challenge for me, but after the third day I think I finally mastered how to work both the autoclaves!) and made sure the running of the day went smoothly for the guests we provided dentistry for.

\section{Q. What does a typical day working for} Crisis at Christmas look like?

As a dental volunteer, you may be working on the dental vans themselves providing dentistry for the guests. This includes fillings, scale and polishes, extractions and delivering oral health advice. At one of our sites we also work with the charity Den-Tech to provide immediate dentures for guests who require teeth replacing.

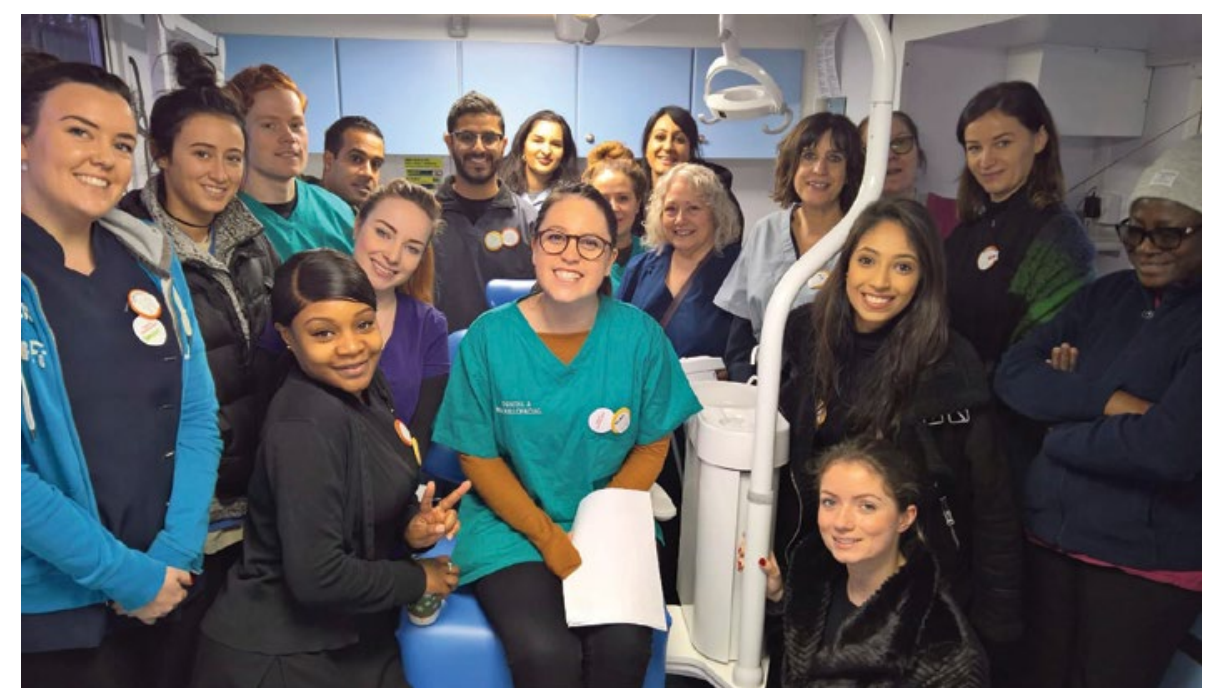

Natalie Bradley and the team running a dental clinic for Crisis at Christmas

very much, sometimes when the patients share their background and how they've ended up where they are, this can be difficult to hear. I do think the experience helps you to be non-judgemental when seeing vulnerable people.

\section{Q. Did you have to give up your own family} celebrations to volunteer?

I vary the time over the Christmas period when I volunteer, so that I can spend a few days with family and friends, but I love spending the festive period with my Crisis family.

\section{'No one should have to wait this long to see a dentist, but I feel in vulnerable groups poor oral health can have a significantly bigger effect on quality of life.'}

\section{Q. How many patients did you see?}

This can vary on the day but I think our record last year at one of our sites was 46 guests! Last year we saw over 400 guests in total over the Christmas period across two London sites.

Q. Were there a lot of challenging cases? I am very used to this group of patients so I didn't think there were any particularly challenging cases. Most of the guests are extremely grateful for the service they receive and we get wonderful feedback each year. I think for some volunteers who may not have come into contact with this group of patients

\section{Q. Have you encouraged friends and} colleagues to volunteer as well?

Yes, I've persuaded many dentists/dental nurses/dental students/dental therapists to volunteer too!

\section{Q. Have you been involved in other charitable pursuits?}

I previously set up a dental van which still runs around East London providing dentistry to the homeless. The van is part of the community dental service in East London run by the Kent Community Health Foundation Trust as part of the homeless project we have been contracted to carry out by NHS England.

\section{Christina Worle}

Background: Christina Worle qualified as a dentist in 2015, is employed by Peninsula Dental Social Enterprise (PDSE) and is studying part time for an MSc in Restorative Dentistry with Peninsula Dental School (University of Plymouth). She has just finished the second year of the three-year course.

Q. Can you tell us about the clinic that you run for vulnerable people?

I run the PDSE community clinic two days per week from the dental school clinical facility in Devonport, Plymouth. Access to routine NHS dentistry in Plymouth is currently poor, with a waiting time of two to three years. No one should have to wait this long to see a dentist, but I feel in vulnerable groups poor oral health can have a significantly bigger effect on quality of life. As well as dental pain, people are often acutely ashamed and embarrassed about the look of their teeth and this really can impact their desire to engage positively with recovery services, other people and wider society. This is something we hope to have a positive impact on.

Q. How did the clinic come about? An awareness of the need to provide dental treatment to this group of people in Plymouth has existed for some time. I began work for PDSE in mid-2017 and the clinic came about in January 2018 when I was asked to treat some patients from a local homeless hostel who had been triaged through an interprofessional engagement project the dental students were running. This went really well, and from there the 
community clinic was born, and continued to grow and develop over the next two years, as we started to work with multiple different organisations.

\section{Q. How do you attract patients to the clinic?}

Vulnerable groups in society have often been labelled hard to reach and engage with. To reach patients who need our help we work in partnership with community organisations that support vulnerable people in Plymouth, such as the Salvation Army, other homeless hostels, drug and alcohol support services, all who can refer patients to us. A big strength of the clinic is that I am able to work flexibly with these organisations to help them support patients to attend. This also helps

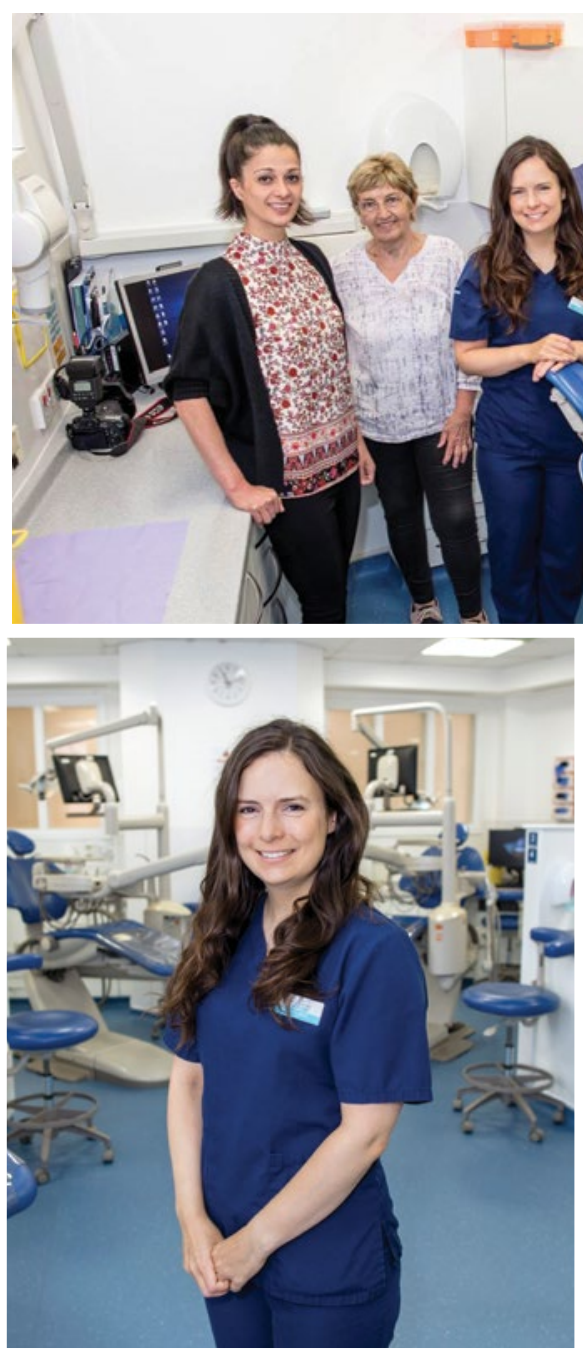

Christina Worle who runs a community dental clinic

minimise the impact of failures to attend and on the day cancellations as I give the partner organisations the freedom to bring another patient at short notice if the person booked is unable to attend.
Q. What sort of treatments do you usually carry out?

A full range of dental treatments are offered, from just a scale and polish through to the removal of all teeth and fabrication of full dentures. Generally, the treatment plans involve a lot of restorations, extractions, and dentures.

Q. Who else works in the clinic with you? We are part of the wider team at the dental school building which includes our fabulous nursing, admin and reception teams. Our community clinic team (pictured) is made up of (from left to right) Martha Paisi, our research lead; Lyndsey Withers, a very experienced volunteer in the community who had been instrumental in informing

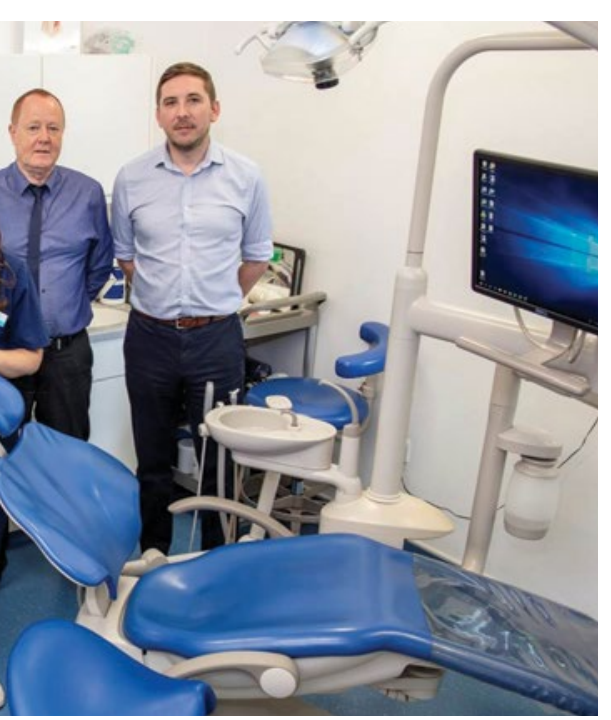

feel excluded from mainstream dentistry; the community clinic is a pro-bono contribution by PDSE to the local community.

\section{Q. Will it be open over the Christmas season?}

Our last community clinic of the year is on Christmas Eve, and then we start again on 6 January, so we do have a short break over Christmas.

Q. Are there many homeless people in your local area?

Yes, definitely. Levels of homelessness and the number of people living in temporary accommodation in Plymouth are higher than the national average. The clinic is situated in Devonport, the most deprived area of Plymouth; our local area is in the top 3\% of the most deprived areas in England.

\section{Q. Is there a large number of one type of} patient eg adult male?

Initially, we treated a lot of adult males as we worked closely with a Salvation Army shelter which mainly catered to men. However, we've taken steps to engage with more vulnerable women and now work closely with PAUSE, an organisation that works with women who have experienced, or are at risk of, repeat removals of children from their care. This includes many of the most deprived and vulnerable women in Plymouth.
Q. Are there any plans to expand the services provided by this clinic? We have just doubled the service provision from one day a week to two. In the future it would be great to increase this again and include areas in the wider south west.

Q. Do you hope to continue in your current role once you have completed your MSc? Definitely, it's the most rewarding and fulfilling part of my week! As well as the dentistry, I love the close working relationships I have with the partner community organisations. objective of ensuring access to dental care for all, but especially to those groups who may 